\title{
Simvastatin attenuates angiotensin II-induced inflammation and oxidative stress in human mesangial cells
}

\author{
FENGXIANG ZHANG ${ }^{1,2^{*}}$, DAPENG SUN ${ }^{2 *}$, JUNJIANG CHEN $^{2}$, \\ NING GUAN $^{2}$, XIAOCHUAN HUO ${ }^{2}$ and HUANJIU XI ${ }^{1,2}$ \\ ${ }^{1}$ Department of Anatomy, China Medical University, Shenyang, Liaoning 110001; ${ }^{2}$ Department of Cardiovascular Surgery, \\ The First Hospital of Liaoning Medical University, Jinzhou, Liaoning 121001, P.R. China
}

Received December 24, 2013; Accepted June 20, 2014

DOI: $10.3892 / \mathrm{mmr} .2014 .2871$

\begin{abstract}
Chronic kidney disease (CKD) is an intractable disease in which inflammation and oxidative stress are important. In the present study, the effect of simvastatin on inflammation and oxidative stress induced by angiotensin II (Ang II) in human mesangial cells (HMCs) and its corresponding mechanism was examined. In the in vitro experiment, HMCs were pretreated either without additives (control group) or with simvastatin at different concentrations $(0,0.1,1$ or $10 \mu \mathrm{M})$ for $1 \mathrm{~h}$ and were then stimulated by Ang II $(1 \mu \mathrm{M})$ for $24 \mathrm{~h}$. Following stimulation, the cells were collected for analysis using quantitative polymerase chain reaction, western blotting and dihydroethidium staining. The supernatant of the cells was collected and analyzed using an enzyme-linked immunosorbent assay. The results demonstrated that simvastatin suppressed the increased mRNA expression of monocyte chemoattractant protein-1, tumor necrosis factor- $\alpha$, interleukin (IL)-1 $\beta$ and IL-6 and the content of reactive oxygen species induced by Ang II in a dose-dependent manner. In addition, simvastatin decreased the protein expression of cyclooxygenase-2 (COX-2), nicotinamide adenine dinucleotide phosphate (NADPH) oxidase and protein kinase $\mathrm{C}$ (PKC) as well as the content of prostaglandin E2 and the phosphorylation level of nuclear factor- $\kappa \mathrm{B}(\mathrm{NF}-\kappa \mathrm{B}) \mathrm{p} 65$ in a dose-dependent manner. Furthermore, simvastatin significantly increased the protein expression of peroxisome proliferator-activated receptor $\gamma$ (PPAR $\gamma$ ). Therefore, simvastatin suppressed inflammation and oxidative stress in Ang II-stimulated HMCs via COX-2, PPAR $\gamma, \mathrm{NF}-\kappa \mathrm{B}, \mathrm{NADPH}$ oxidase and PKCs, thereby exerting a protective effect on CKD.
\end{abstract}

Correspondence to: Professor Huanjiu Xi, Department of Anatomy, China Medical University, No. 92 of Beima Road, Heping, Shenyang, Liaoning 110001, P.R. China

E-mail: canghaiguanri@126.com

*Contributed equally

Key words: human mesangial cells, angiotensin II, simvastatin, inflammation, oxidative stress

\section{Introduction}

Chronic kidney disease (CKD) is an intractable disease, which continues to increase worldwide and has increased the financial burden on health care systems (1). It is therefore necessary to elucidate the underlying mechanism and to develop an additional treatment strategy to slow the progression of CKD. Previous studies have demonstrated that a persistent inflammatory response was a characteristic of CKD in animal models and in patients, which revealed the importance of inflammation in renal injury $(2,3)$. In addition, oxidative stress also accelerated the progression of CKD. A review of previous studies found that reactive oxygen species (ROS) increased in a graded manner as renal function deteriorated and identified an inverse correlation between oxidative stress and glomerular filtration rate (4). Furthermore, inhibition of nicotinamide adenine dinucleotide phosphate (NADPH) oxidase, which produces ROS, was beneficial to renal injury $(5,6)$, thus it is an effective treatment strategy to suppress inflammation and oxidative stress in CKD.

Statins (3-hydroxy-3-methylglutaryl-coenzyme A reductase inhibitors) are drugs with potent lipid-lowering effects. In addition to their cholesterol-lowering properties, statins have pleiotropic effects (7). Statins suppress mesangial cell proliferation, prevent the decrease in glomerular filtration and the deterioration of renal function in patients with nephropathy (8). Therefore, statins may provide a beneficial therapy in preventing and delaying the progression of CKD. However, the exact mechanism remains to be fully elucidated.

Mesangial cells are a major glomerular cell type and are involved in inflammatory reactions and oxidative stress in the kidney (9) leading to CKD (10). In kidney injury, mesangial cells are the major target of angiotensin II (Ang II), which accelerates inflammation and other adverse actions. Thus, in the present study, the effect of simvastatin on human mesangial cells (HMCs) in the presence of Ang II was examined, and the hypothesis that the mechanism underlying the protective effect of simvastatin is through attenuating inflammation and oxidative stress was assessed.

\section{Materials and methods}

Cell culture. HMCs were purchased from the American Type Cell Collection (Manassas, VA, USA) and cultured in 
RPMI-1640 containing 10\% fetal bovine serum. Mesangial cells were incubated at $37^{\circ} \mathrm{C}$ in a humidified incubator containing $5 \% \mathrm{CO}_{2}$. The cells up to the 4 th passage were used and were plated in 6-well plates and cells at $90 \%$ confluence were used for experiments The control group was treated without additives and the other four groups were pretreated with simvastatin at different concentrations $(0,0.1,1$ or $10 \mu \mathrm{M})$ for $1 \mathrm{~h}$ and then stimulated by Ang II $(1 \mu \mathrm{M})$ for $24 \mathrm{~h}$. Following stimulation, all the cells were collected.

RNA extraction and quantitative polymerase chain reaction $(q P C R)$. The cells were harvested and total RNA was extracted using TRIzol reagent (Invitrogen Life Technologies, Carlsbad, CA, USA). cDNA was synthesized and qPCR was performed according to the manufacturer's instructions. Relative mRNA levels for target genes were analyzed with the comparative CT method. Human GAPDH levels served as an internal control. The primer sequences used were as follows: monocyte chemoattractant protein-1 (MCP-1), forward 5'-TGTTGATGTGAAACATTATGCC-3' and reverse 5'-AATGATTCTTGCAAAGACCCTC-3'; tumor necrosis factor- $\alpha$ (TNF- $\alpha)$, forward 5'-TTCGAGAAGATGATCTGATGC-3' and reverse 5'-TCAGCCTCTTCTCCTTCCT-3'; interleukin (IL)-1 $\beta$, forward 5'-ATGGGATAACGAGGCTTATG-3' and reverse 5'-CAAGGCCACAGGTATTTTGTC-3'; IL-6, forward 5'-ATGAACTCCTTCTCCACAAGCGC-3' and reverse 5'-GAAGAGCCCTCAGGCTGGACTG-3'; cyclooxygenase-2 (COX-2), forward 5'-TCCCTGAGCATCTACGGTTT-3' and reverse 5'-TACTCTGTTGTGTTCCCGCA-3' and GAPDH, forward 5'-GCACCGTCAAGGCTGAGAAC-3' and reverse 5'-ATGGTGGTGAAGACGCCAGT-3'. All experiments were repeated three times and the mean values were derived.

Western blot analysis. The protein was extracted from the five groups using radioimmunoprecipitation assay lysis buffer with a protease inhibitor (phenylmethanesulfonyl fluroide; Beyotime, Beijing, China) and protein concentrations were determined using a bicinchoninic acid protein assay. Equal quantities of protein were resolved by $10 \%$ SDS-PAGE and transferred onto nitrocellulose membranes (Plano, TX, USA), which were inhibited with 5\% skimmed milk for $2 \mathrm{~h}$. Subsequently, the membranes were incubated with specific primary antibodies at $4^{\circ} \mathrm{C}$ overnight, and then horseradish peroxidase-conjugated secondary antibodies (goat anti-mouse polyclonal antibody to IgG or goat anti-rabbit polyclonal antibody to $\mathrm{IgG}$ ) against the primary antibody was added at room temperature for $2 \mathrm{~h}$. Finally, the immunoreactive bands were visualized using enhanced chemiluminescence plus reagents (Millipore, Plano, TX, USA). $\beta$-actin was used as an endogenous loading control. All experiments were repeated three times and the mean values were derived.

The primary antibodies used in the experiments were as follows: rabbit polyclonal anti-NOX2 (1:1,000; Abcam, Cambridge, UK), rabbit monoclonal anti-protein kinase $\mathrm{C} \alpha$ (PKC $\alpha ; 1: 1,000 ;$ Abcam), rabbit monoclonal anti-PKC $\beta 1$ (1:1,000; Abcam), rabbit polyclonal anti-COX-2 (1:1,000; Abcam), rabbit polyclonal anti-peroxisome proliferator activated receptor $\gamma$ (PPAR $\gamma ; 1: 1,000$; Abcam), rabbit polyclonal anti-nuclear factor- $\kappa \mathrm{B}(\mathrm{NF}-\kappa \mathrm{B})$ p65 (1:1,000; Cell Signaling
Technology, Inc., Danvers, MA, USA), rabbit polyclonal anti-(phosphorylation-NF-кB p65; 1:1,000; Cell Signaling Technology, Inc.), rabbit monoclonal anti- $\beta$-actin (1:1,000; Cell Signaling Technology, Inc.) and rabbit polyclonal anti-p47 $7^{\text {phox }}$ (1:1,000; Millipore).

Enzyme-linked immunosorbent assay (ELISA). The supernatant of mesangial cells among all groups were collected and stored at $-80^{\circ} \mathrm{C}$. The levels of prostaglandin $\mathrm{E} 2\left(\mathrm{PGE}_{2}\right)$ were assessed with an ELISA kit according to the manufacturer's instructions (R\&D Systems, Minneapolis, MN, USA).

Statistical analysis. The values are expressed as the mean \pm standard error of the mean. The differences between any two groups were analyzed by Student's t-test and for more than two groups by one-way analysis of variance. $\mathrm{P}<0.05$ was considered to indicate a statistically significant difference.

\section{Results}

Simvastatin downregulates Ang II-induced proinflammatory cytokine expression in HMCs. Ang II regulates the synthesis of proinflammatory cytokines and chemokines, including MCP-1, TNF- $\alpha$, IL-1 $\beta$ and IL-6 $(11,12)$. In the present study, the mRNA expression levels of MCP-1, TNF- $\alpha$, IL- $1 \beta$ and IL-6 were determined by qPCR. The results demonstrated that in HMCs, 1 and $10 \mu \mathrm{m}$ simvastatin significantly decreased the expression levels of proinflammatory cytokines compared with the control group ( $\mathrm{P}<0.05$; Fig. 1), whereas no significant difference in the expression of these cytokines was observed between $0.1 \mu \mathrm{m}$ simvastatin and the control group ( $\mathrm{P}>0.05$; Fig. 1), indicating that simvastatin downregulated the inflammatory response in HMCs in a dose-dependent manner.

Simvastatin suppresses Ang II-induced oxidative stress in HMCs. The level of ROS in HMCs, as determined by dihydroethidium staining, was increased significantly following Ang II stimulation ( $\mathrm{P}<0.05$; Fig. $2 \mathrm{~A}$ and $\mathrm{B})$, however, this effect was attenuated by simvastatin in a dose-dependent manner $(\mathrm{P}<0.05$; Fig. 2A and B). Increases in renal NADPH oxidase activity and activation of the PKC system are important in oxidative stress and kidney damage $(13,14)$. Therefore, the present study also examined the expression levels of NADPH oxidase subunits (NOX2 and $4^{\text {phox }}$ ) and PKC isoforms (PKC $\alpha$ and PKC $\beta 1$ ) in cultured mesangial cells. As shown in Fig. 2C and D, Ang II significantly increased the expression levels of the above proteins, while simvastatin reversed the effect of Ang II in a dose-dependent manner. These results demonstrated that simvastatin reduced oxidative stress by suppressing the NADPH oxidase and PKC signaling pathways.

Simvastatin inhibits COX-2 expression in HMCs. The present study also examined the mRNA and protein expression of COX-2 in HMCs stimulated with Ang II and found that, compared with the control group, the mRNA and protein expression of COX-2 in the Ang II group was markedly increased. However, it was significantly lower in the 1 and $10 \mu \mathrm{m}$ simvastatin groups than in the Ang II and $0.1 \mu \mathrm{m}$ simvastatin groups $(\mathrm{P}<0.05$; Fig. $3 \mathrm{~A}$ and $\mathrm{B})$. In addition to its effect on COX-2 expression, Ang II significantly increased the 
A

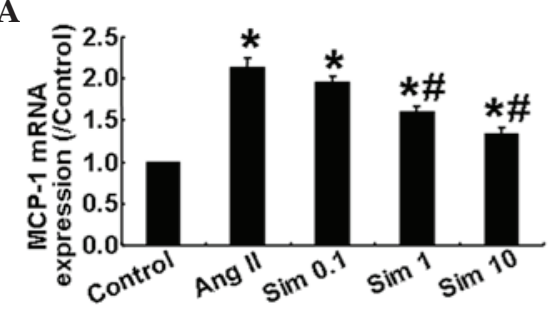

C

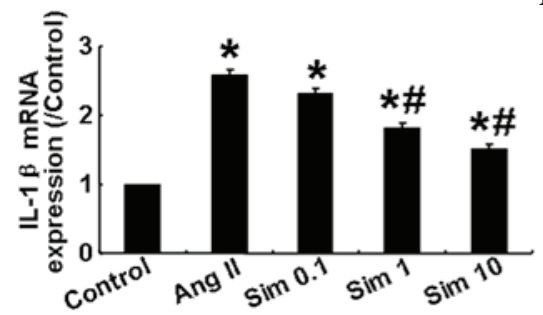

B

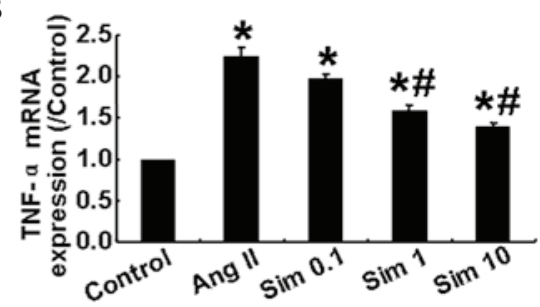

D

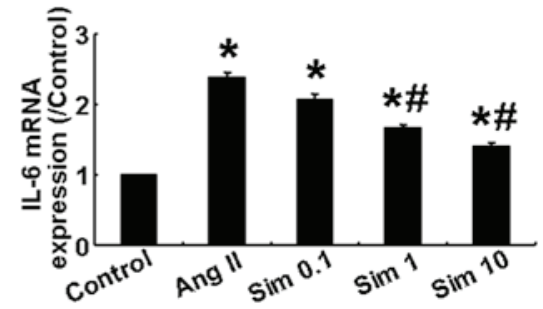

Figure 1. Effects of simvastatin on the mRNA expression of proinflammatory factors in human mesangial cells. (A) mRNA expression of MCP-1 in the five groups. (B) mRNA expression of TNF- $\alpha$ in the five groups. (C) mRNA expression of IL-1 $\beta$ in the five groups. (D) mRNA expression of IL-6 in the five groups. Sim 0.1, $0.1 \mu \mathrm{m}$ simvastatin group; Sim 1, $1 \mu \mathrm{m}$ simvastatin group; Sim 10, $10 \mu \mathrm{m}$ simvastatin group. *P<0.05, vs. control group; ${ }^{*} \mathrm{P}<0.05$, vs. Ang II group. MCP-1, monocyte chemoattractant protein-1; TNF- $\alpha$, tumor necrosis factor- $\alpha$; IL, interleukin; Ang II, angiotensin II.

A
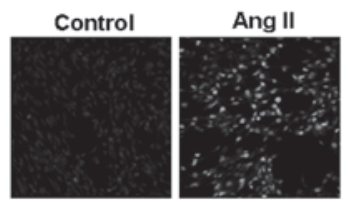

$\operatorname{sim} 0.1$

C
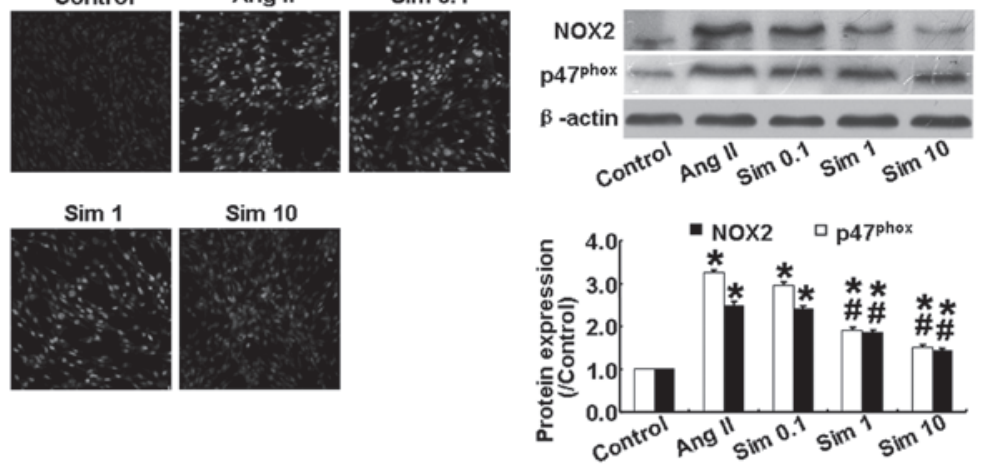

B

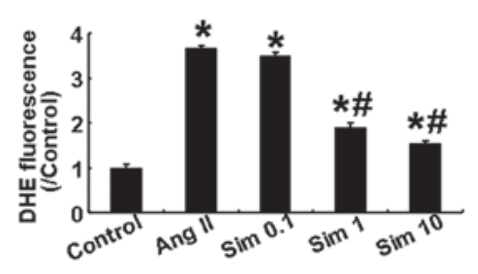

D

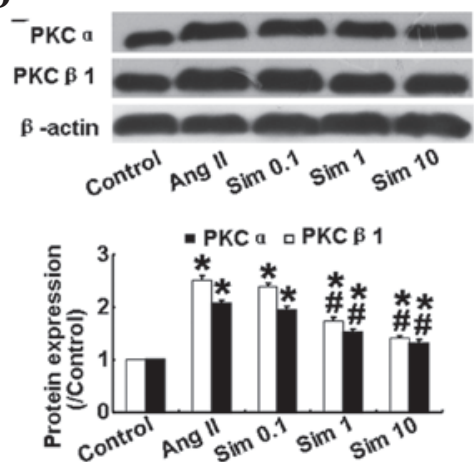

Figure 2. Effects of simvastatin on oxidative stress and the expression of NADPH oxidase subunits and the PKC isoforms in human mesangial cells (A) Representative DHE staining in the five groups. (B) Quantitative analysis of A. (C) Protein expression of NOX2 and p47 phox in the five groups by western blotting and quantitative analysis. (D) Protein expression of PKC $\alpha$ and $\mathrm{PKC} \beta 1$ in the five groups by western blotting and quantitative analysis. Sim $0.1,0.1 \mu \mathrm{m}$ simvastatin group; Sim 1, $1 \mu \mathrm{m}$ simvastatin group; Sim 10, $10 \mu \mathrm{m}$ simvastatin group. " $\mathrm{P}<0.05$, vs. control group; ${ }^{~ P}<0.05$, vs. Ang II group. NADPH, nicotinamide adenine dinucleotide phosphate; PKC, protein kinase C; NOX2, NADPH oxidase; Ang II, angiotensin II; Sim, simvostatin; DHE, dihydroethidium.

production of $\mathrm{PGE}_{2}$, while simvastatin markedly suppressed this effect in a dose-dependent manner ( $\mathrm{P}<0.05$; Fig. $3 \mathrm{C}$ ). These results demonstrated that Ang II induced COX-2 expression in HMCs, which was partially inhibited by simvastatin treatment.
Simvastatin suppresses PPAR $\gamma$ expression and $N F-\kappa B$ activation in HMCs. Ang II has been demonstrated to reduce the decrease in expression of PPAR $\gamma$, which can further augment inflammation (15). As shown in Fig. 4A, Ang II significantly decreased the expression of PPAR $\gamma$ compared with the control 
A

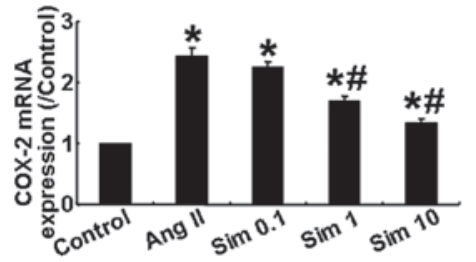

B

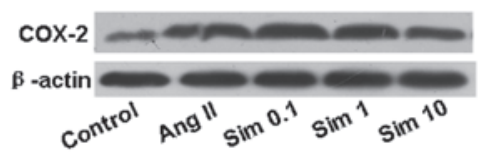

$\mathbf{C}$

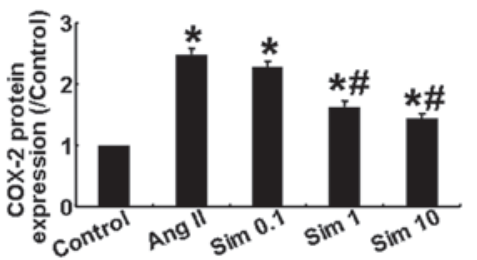

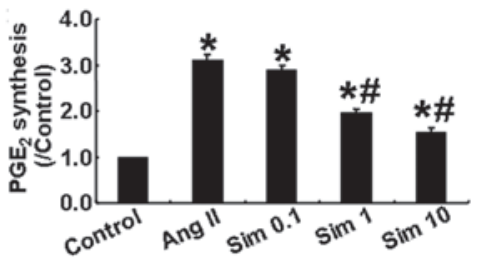

Figure 3. Effects of simvastatin on the expression of COX-2 and the production of $\mathrm{PGE}_{2}$ in human mesangial cells. (A) mRNA expression of COX-2 in the five groups. (B) Protein expression of COX-2 in the five groups by western blotting and quantitative analysis (C) Production levels of $\mathrm{PGE}_{2}$ in the five groups by ELISA. Sim 0.1, $0.1 \mu \mathrm{m}$ simvastatin group; Sim 1, $1 \mu \mathrm{m}$ simvastatin group; Sim 10, $10 \mu \mathrm{m}$ simvastatin group. ${ }^{*} \mathrm{P}<0.05$, vs. control group; ${ }^{*} \mathrm{P}<0.05$, vs. Ang II group. COX-2, cyclooxygenase-2; $\mathrm{PGE}_{2}$, prostaglandin E2; Ang II, angiotensin II; Sim, simvastatin.
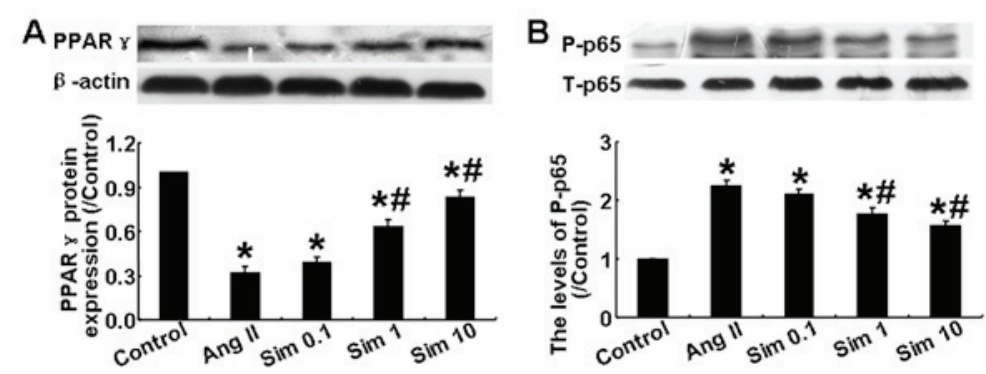

Figure 4. Effects of simvastatin on the expression of PPAR $\gamma$ and the phosphorylation level of NF-кB p65 in human mesangial cells. (A) Protein expression of PPAR $\gamma$ in the five groups by western blotting and quantitative analysis. (B) Phosphorylation levels of NF- $\mathrm{kB}$ p65 in the five groups by western blotting and quantitative analysis. Sim 0.1, $0.1 \mu \mathrm{m}$ simvastatin group. Sim 1, $1 \mu \mathrm{m}$ simvastatin group; Sim 10, $10 \mu \mathrm{m}$ simvastatin group. ${ }^{*} \mathrm{P}<0.05$, vs. control group; ${ }^{\# P}<0.05$,

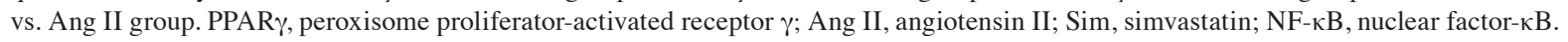

group, while simvastatin reversed the Ang II-induced decrease in PPAR $\gamma$ expression at doses of 1 and $10 \mu \mathrm{m}$. The phosphorylation level of $\mathrm{NF}-\kappa \mathrm{B}$ p65 among the five groups was also examined by western blot analysis. The results demonstrated that Ang II significantly increased the levels of phosphorylation of $\mathrm{NF}-\kappa \mathrm{B}$ p65, while 1 and $10 \mu \mathrm{m}$ simvastatin reversed this increase $(\mathrm{P}<0.05$; Fig. 4B). However, a simvastatin concentration of $0.1 \mu \mathrm{m}$ did not have a significant effect. These results demonstrated that simvastatin suppressed the effect of Ang II on the expression of PPAR $\gamma$ and on the activation of $\mathrm{NF}-\kappa \mathrm{B}$ in HMCs.

\section{Discussion}

CKD is an intractable disease worldwide and a rational therapy is critical for improving public health. Statins have been demonstrated to have organ-protective properties independent of their cholesterol-lowering effects. In the present study, the effect of simvastatin on HMCs stimulated by Ang II was examined. The results demonstrated that simvastatin significantly suppressed the inflammatory response by inhibiting COX-2 expression and NF- $\kappa \mathrm{B}$ activation, and reversing the expression of PPAR $\gamma$ suppressed by Ang II. In addition, simvastatin alleviated oxidative stress by decreasing the expression of NADPH oxidase and PKCs. Therefore, simvastatin may have a beneficial effect in renal injury.
The renin-angiotensin system (RAS) has been demonstrated to be important in the pathogenesis of CKD. Ang II is the major product of RAS and its principle target in the kidney is the mesangial cells. Ang II affects the local hemodynamics in the kidney and induces glomerular mesangial dysfunction, mesangial cell hypertrophy and proliferation, or promotes extracellular matrix deposition, which appears to be directly linked to inflammation and oxidative stress (16). Therefore, in the present study, HMCs were selected and stimulated with Ang II as an in vitro model to examine the effect of simvastatin on CKD and the corresponding mechanism.

Inflammation is important in numerous diseases, including progressive renal disease, and CKD has been viewed as a chronic inflammatory disease $(17,18)$. Persistent inflammation inside the kidney affects the local hemodynamics and induces glomerular injury and renal fibrosis, which promotes renal dysfunction and contributes to the progression of kidney disease $(19,20)$. Ang II, a known inflammatory mediator, activates the expression of a diverse range of proinflammatory factors in the kidney and contributes to renal injury (21). In the present study, Ang II significantly increased the expression of MCP-1, TNF- $\alpha$, IL-1 $\beta$ and IL-6 in HMCs, while simvastatin suppressed the effect of Ang II on the expression of proinflammatory factors in a dose-dependent manner, indicating that simvastatin had anti-inflammatory effects in CKD. 
Oxidative stress has emerged as an important pathogenic factor in numerous renal diseases, including acute and chronic renal failure (22). ROS produce oxidative stress and overproduction or reduced elimination of ROS has a toxic effect on cells and causes damage to tissues (23). Previous studies demonstrated that inhibition of ROS production was beneficial in experimental and human kidney disease (23). There is increasing evidence that Ang II directly promotes the production of ROS via NADPH oxidase in mesangial cells, which is important in glomerular injury (24). In the present study, the effect of simvastatin on the production of ROS in HMCs stimulated with Ang II was examined. The results indicated that, compared with the control group, the content of ROS was significantly increased in the Ang II group and was suppressed in the simvastatin groups in a dose-dependent manner. Among the three doses of simvastatin, 1 and $10 \mu \mathrm{m}$ significantly decreased the content of ROS, suggesting that simvastatin has an anti-oxidative stress effect in CKD.

The present study also detected the mechanism of simvastatin on anti-inflammation and anti-oxidative stress in HMCs stimulated with Ang II. PPAR $\gamma$ is a member of the nuclear receptor superfamily of transcription factors, which ameliorates the inflammatory response (25). Inhibition of PPAR $\gamma$ activity, involved in the pathogenesis of inflammation and its agonists, exerted an anti-inflammatory effect by downregulating the transcription of NF-kB (26). In addition, it was confirmed that PPAR $\gamma$ was present in mesangial cells and PPAR $\gamma$ agonists modulated the proliferation and differentiation of mesangial cells and has been effective in the therapy of renal dysfunction (27). NF- $\mathrm{KB}$ modulates the levels of genes involved in inflammatory responses and the activation of NF- $\mathrm{KB}$ in mesangial cells has a major pathogenic effect on inflammatory renal disease $(28,29)$. In addition, COX-2 catalyzes the conversion process of arachidonic acids to prostaglandins and upregulates the expression of proinflammatory chemokines in the kidney (30). Therefore, the present study examined the effects of simvastatin on the expression of PPAR $\gamma$ and COX-2 and the phosphorylation level of NF- $\kappa B$ p65 in HMCs. Ang II was found to significantly increase the expression of COX-2 and the level of phosphorylation of NF- $\kappa \mathrm{B}$ p65, and decrease the expression of PPAR $\gamma$. However, 1 and $10 \mu \mathrm{m}$ simvastatin clearly reversed the effects of Ang II. Simvastatin may therefore have an anti-inflammatiory effect in CKD through regulating the expression of PPAR $\gamma$ and COX-2 and the activation of NF- $\mathrm{\kappa B}$.

Oxidative stress is important in CKD and the major producer of this is ROS. A previous study demonstrated that NADPH oxidase was the predominant enzyme in ROS production and was recognized as an important factor in cell proliferation and extracellular matrix accumulation in renal disease (31). NADPH oxidase is composed of two membrane-associated components, $\mathrm{p} 22^{\text {phox }}$ and NOX2 and four cytosolic components ( $\mathrm{p} 47^{\text {phox }}, \mathrm{p} 67^{\text {phox }}, \mathrm{p} 40^{\text {phox }}$ and rac-1/2). The subunits NOX2 and $\mathrm{p} 47^{\text {phox }}$ are mainly expressed in the kidney (32). Thus, the present study detected the expression of NOX2 and p $47^{\text {phox }}$ in HMCs and found that simvastatin reversed the Ang II-induced increase in NOX2 and $447^{\text {phox }}$ in a dose-dependent manner, reaching its maximum effect at $10 \mu \mathrm{m}$ simvastatin. In addition, activation of the PKC system is known to be important in the pathophysiology of kidney damage (33). There is evidence indicating that PKC mediates the Ang II-induced activation of NADPH oxidase and then increases the production of ROS (34). The PKC system has several isozymes, including PKC $\alpha$ and PKC $\beta 1$, which have been identified in mesangial cells (35). The present study demonstrated that Ang II significantly increased the expression of PKC $\alpha$ and PKC $\beta 1$, and simvastatin suppressed the effect of Ang II in a dose-dependent manner. Therefore, simvastatin may inhibit oxidative stress induced by Ang II through suppressing the expression of NADPH oxidase and PKCs.

In conclusion, simvastatin ameliorated Ang II-induced inflammation and oxidative stress in a dose-dependent manner. The possible underlying mechanisms of the simvastatin-mediated effects may involve the reduced expression of COX-2, NADPH oxidase and PKCs, the activation of NF- $\kappa \mathrm{B}$ and the increased expression of PPAR $\gamma$.

\section{Acknowledgements}

The present study was supported by a grant from the Liaoning Province Natural Science Foundation (no. 2013022010).

\section{References}

1. Ruggenenti P, Cravedi P and Remuzzi G: Mechanisms and treatment of CKD. J Am Soc Nephrol 23: 1917-1928, 2012.

2. Stenvinkel P, Ketteler M, Johnson RJ, et al: IL-10, IL-6, and TNF-alpha: central factors in the altered cytokine network of uremia - the good, the bad, and the ugly. Kidney Int 67: 1216-1233, 2005.

3. Abbate M, Zoja C and Remuzzi G: How does proteinuria cause progressive renal damage? J Am Soc Nephrol 17: 2974-2984, 2006

4. Cachofeiro V, Goicochea M, de Vinuesa SG, Oubina P, Lahera V and Luno J: Oxidative stress and inflammation, a link between chronic kidney disease and cardiovascular disease. Kidney Int Suppl: S4-S9, 2008.

5. Yi F, Xia M, Li N, Zhang C, Tang L and Li PL: Contribution of guanine nucleotide exchange factor Vav2 to hyperhomocysteinemic glomerulosclerosis in rats. Hypertension 53: 90-96, 2009.

6. Tian N, Thrasher KD, Gundy PD, Hughson MD and Manning RD, Jr: Antioxidant treatment prevents renal damage and dysfunction and reduces arterial pressure in salt-sensitive hypertension. Hypertension 45: 934-939, 2005.

7. Meng X, Zhang K, Li J, et al: Statins induce the accumulation of regulatory $\mathrm{T}$ cells in atherosclerotic plaque. Mol Med 18: 598-605, 2012.

8. Athyros VG, Papageorgiou AA, Elisaf M and Mikhailidis DP: Statins and renal function in patients with diabetes mellitus. Curr Med Res Opin 19: 615-617, 2003.

9. Imaizumi T, Aizawa-Yashiro T, Tsuruga K, et al: Melanoma differentiation-associated gene 5 regulates the expression of a chemokine CXCL10 in human mesangial cells: implications for chronic inflammatory renal diseases. Tohoku J Exp Med 228: 17-26, 2012.

10. Schlondorff D and Banas B: The mesangial cell revisited: no cell is an island. J Am Soc Nephrol 20: 1179-1187, 2009.

11. Ruiz-Ortega M, Ruperez M, Lorenzo O, et al: Angiotensin II regulates the synthesis of proinflammatory cytokines and chemokines in the kidney. Kidney Int 62: S12-S22, 2002.

12. Zhong J, Guo D, Chen CB, et al: Prevention of angiotensin II-mediated renal oxidative stress, inflammation, and fibrosis by angiotensin-converting enzyme 2. Hypertension 57: 314-322, 2011.

13. Thallas-Bonke V, Thorpe SR, Coughlan MT, et al: Inhibition of NADPH oxidase prevents advanced glycation end product-mediated damage in diabetic nephropathy through a protein kinase $\mathrm{C}$-alpha-dependent pathway. Diabetes 57: 460-469, 2008 
14. Kitada M, Koya D, Sugimoto T, et al: Translocation of glomerular p47phox and p67phox by protein kinase C-beta activation is required for oxidative stress in diabetic nephropathy. Diabetes 52: 2603-2614, 2003.

15. Kintscher U,Lyon CJ and Law RE: Angiotensin II,PPAR-gamma and atherosclerosis. Front Biosci 9: 359-369, 2004.

16. Pearse DD, Tian RX, Nigro J, Iorgulescu JB, Puzis L and Jaimes EA: Angiotensin II increases the expression of the transcription factor ETS-1 in mesangial cells. Am J Physiol Renal Physiol 294: F1094-F1100, 2008.

17. Varghese Z, Fernando R, Moorhead JF, Powis SH and Ruan XZ: Effects of sirolimus on mesangial cell cholesterol homeostasis: a novel mechanism for its action against lipid-mediated injury in renal allografts. Am J Physiol Renal Physiol 289: F43-F48, 2005.

18. Stenvinkel P, Heimburger O, Paultre F, et al: Strong association between malnutrition, inflammation, and atherosclerosis in chronic renal failure. Kidney Int 55: 1899-1911, 1999.

19. Pawluczyk IZ, Tan EK and Harris KP: Rat mesangial cells exhibit sex-specific profibrotic and proinflammatory phenotypes. Nephrol Dial Transplant 24: 1753-1758, 2009.

20. Zhang M, Gao X, Wu J, et al: Oxidized high-density lipoprotein enhances inflammatory activity in rat mesangial cells. Diabetes Metab Res Rev 26: 455-463, 2010.

21. Theuer J, Dechend R, Muller DN, et al: Angiotensin II induced inflammation in the kidney and in the heart of double transgenic rats. BMC Cardiovasc Disord 2: 3, 2002.

22. Presti RL, Carollo C and Caimi G: Wine consumption and renal diseases: new perspectives. Nutrition 23: 598-602, 2007.

23. Li JM and Shah AM: ROS generation by nonphagocytic NADPH oxidase: potential relevance in diabetic nephropathy. J Am Soc Nephrol 14: S221-S226, 2003.

24. Jaimes EA, Galceran JM and Raij L: Angiotensin II induces superoxide anion production by mesangial cells. Kidney Int 54 775-784, 1998

25. Jiang C, Ting AT and Seed B: PPAR-gamma agonists inhibit production of monocyte inflammatory cytokines. Nature 391: 82-86, 1998.
26. Wu X and Li L: Rosiglitazone suppresses lipopolysaccharide-induced matrix metalloproteinase-2 activity in rat aortic endothelial cells via Ras-MEK1/2 signaling. Int J Cardiol 158: 54-58, 2012.

27. Asano T, Wakisaka M, Yoshinari M, et al: Peroxisome proliferator-activated receptor gammal (PPARgamma1) expresses in rat mesangial cells and PPARgamma agonists modulate its differentiation. Biochim Biophys Acta 1497: 148-154, 2000.

28. Rangan G, Wang Y and Harris D: NF-kappaB signalling in chronic kidney disease. Front Biosci (Landmark Ed) 14 3496-3522, 2009.

29. Wang Y, Zhang MX, Meng X, et al: Atorvastatin suppresses LPS-induced rapid upregulation of Toll-like receptor 4 and its signaling pathway in endothelial cells. Am J Physiol Heart Circ Physiol 300: H1743-H1752, 2011.

30. Zahner G, Schaper M, Panzer U, et al: Prostaglandin EP2 and EP4 receptors modulate expression of the chemokine CCL2 (MCP-1) in response to LPS-induced renal glomerular inflammation. Biochem J 422: 563-570, 2009.

31. Zhang L, Pang S, Deng B, et al: High glucose induces renal mesangial cell proliferation and fibronectin expression through $\mathrm{JNK} / \mathrm{NF}-\kappa \mathrm{B} / \mathrm{NADPH}$ oxidase/ROS pathway, which is inhibited by resveratrol. Int J Biochem Cell Biol 44: 629-638, 2012.

32. Jiang F, Zhang Y and Dusting GJ: NADPH oxidase-mediated redox signaling: roles in cellular stress response, stress tolerance, and tissue repair. Pharmacol Rev 63: 218-242, 2011.

33. Oudit GY, Liu GC, Zhong J, et al: Human recombinant ACE2 reduces the progression of diabetic nephropathy. Diabetes 59: $529-538,2010$.

34. Korchak HM and Kilpatrick LE: Roles for beta II-protein kinase $\mathrm{C}$ and RACK1 in positive and negative signaling for superoxide anion generation in differentiated HL60 cells. J Biol Chem 276: 8910-8917, 2001.

35. Wei XF, Zhou QG, Hou FF, Liu BY and Liang M: Advanced oxidation protein products induce mesangial cell perturbation through PKC-dependent activation of NADPH oxidase. Am J Physiol Renal Physiol 296: F427-F437, 2009. 